\title{
Drug testing: Who pays? Who benefits?
}

\author{
NANCY OLIVIERI
}

\section{Jill A Fisher, Adverse Events: Race, Inequality, and the Testing of New Pharmaceuticals New York University Press, 2020, 336 pgs, \$30.00, ISBN 9781479862160 (paperback) 9781479877997(hardcover).}

The public is not under any illusion about the crimes and misdemeanours of the pharmaceutical industry. As of 2019, in the US, the industry ("Pharma") was considered more negatively than oil and banking - and the US government (1). Yes, until recently, at least in the US - Donald Trump enjoyed a better public rating than Big Pharma.

Of course, at the moment, Pharma is enjoying an uptick in popular support, owing to its participation in the development of vaccines. But for many this does not undo or reverse what has been termed "the horrible history of Big Pharma" (2) over the past half-century, as outlined in several recent scholarly books (3-6). No doubt, readers who especially appreciate these books include people who, like me, became professional and personal targets of Pharma. I find myself wishing I'd read these books before I became engaged in a bitter conflict with a Pharma CEO about the safety of patients in clinical trials. Adverse Events by Jill Fisher, a Professor of Social Medicine at the University of North Carolina at Chapel Hill, is one book which would have better prepared me for the long struggle that followed.

Fisher's book focuses on Phase 1 clinical trials, in which humans (who are not patients) are first exposed to a drug that has not yet been approved for sale. The results of Phase 1 trials determine whether patients may later be exposed in Phase 2 trials and, if all goes well, in larger numbers in Phase 3 trials. The primary goal of Phase 1 trials is to determine whether, and to what extent, healthy people may become

Author: Nancy Olivieri (nancy@hemoglobal.org), Professor, Pediatrics, Medicine and Public Health Sciences, University of Toronto, Toronto, Ontario, CANADA; Senior Scientist, Toronto General Hospital, Toronto, Ontario, CANADA M5G 2 C4.

To cite: Olivieri N. Drug testing: Who pays? Who benefits? Indian J Med Ethics. Published online on June 28, 2021. DOI: 10.20529/IJME.2021.049.

Manuscript Editor: Sanjay A Pai

c Indian Journal of Medical Ethics 2021 sick during short-term exposure to a drug. In short, Phase 1 trials are generally the first step in the path to Pharma profit.

While many may be aware that Pharma companies sponsor most clinical trials, fewer may realise that $90 \%$ of drugs "developed" by Pharma are ultimately shown to be poorly evaluated, have no tangible therapeutic benefit, or to be more harmful than useful (7). This raises the fundamental question of why Pharma should be trusted to "contribute" to the testing of the drugs from whose sale it will, eventually, reap obscene profits, and Fisher's book may convince you that it should not.

Fisher insists however that "this is not a story about big bad Pharma, although it could be." She positions the testing of drugs within a larger social context, with at least three important themes, viz, the particular untrustworthiness of Pharma-managed Phase 1 trials; the abuse and exploitation of vulnerable individuals who participate in these trials; and the issue of whether, in Phase 1 trials, consent can truly be "informed."

First, as to untrustworthiness. Ostensibly, the goal of Phase 1 trials is to evaluate the safety of a drug in individuals who are, allegedly, similar to those who will ultimately be treated in real life. In reality, many Phase 1 trial findings have little applicability to the patients who will eventually take these drugs, partly because in many such trials, patients are carefully "selected." Or not selected. For example, many Phase 1 trials avoid enrolling women, and prioritise enrollment of young patients, although in the real world, women and older individuals are the primary consumers of drugs. More devious selections operate: if an experimental drug is suspected to have the adverse effect of a (possibly dangerous) reduction of blood pressure, volunteers with blood pressures in the highest range may be "selected" for enrolment, to help portray the drug as safe - when it may not be. With admirable restraint, Fisher terms these deceptive practices "validity compromising behaviours" ( $p$ 166). One can think of a few other choice names for them.

Such dishonesty is in "everyone's interest": not only that of Pharma, but of the staff managing Phase 1 trials, which are now generally conducted in the settings of companies known as contract research organisations (CROs). Anxious to win and keep Pharma business, CROs aim to deliver "the right kind of data." Volunteers themselves may fail to report adverse effects of the drugs, justifiably fearing reduced compensation. 
Worse: individuals who don't report adverse effects, appear resistant to adverse effects, or both, may be repeatedly recruited (yes this is against the rules) into an "actively curated, and relatively circumscribed" (p. 17) group of patients, who likely differ significantly from the general population in the ability to tolerate drugs.

We are led by Fisher to the inescapable conclusion that Phase 1 trials are untrustworthy and so, as might be argued, the risks which subjects undertake (below) in those trials are unjustified.

Although I had spent many years conducting drug trials, I didn't know much about Phase 1 trials before reading Fisher's work. Nevertheless, many of her observations are sadly familiar, as illustrated by recounting a small slice of my own experience. In the late 1980s, in my own patients at Toronto's Hospital for Sick Children, I began trials of deferiprone, an experimental drug. Conducted in a turn of the century ward repurposed as the Hospital's "Clinical Investigation Unit," supported with public funds, my trials were another world from those of today. But eventually they came under the long arm of Pharma. As the first promising results emerged five years after the trials began, I was advised that to develop deferiprone, I would require a commercial sponsor to carry further trials forward - advice I accepted, believing that there was no alternative. Perhaps at that time, there was no alternative. Fisher's book may help us to consider whether it is time for a change.

As luck would have it, a Pharma CEO, Barry Sherman, agreed to add modest funds to my ongoing public support (in exchange for obtaining worldwide patent rights). Later, when serious concerns about deferiprone's safety emerged, Sherman terminated the trials, and threatened "all legal remedies" should I disclose my concerns. Eighteen years of legal proceedings followed, during which the adverse actions of my academic institution deepened and extended the conflict (8) which, as of 2021, shows no sign of abating (9).

My experience parallels the common - albeit usually more subtle - approach of Pharma's "management" of adverse events, including in Phase 1 trials. As Fisher observes "Pharma utilizes a 'harm liability calculus' that permits injury and death [if] the drug's profits outstrip what might be paid in lawsuits" ( $p$ 158). Adverse effects may be "reframed;" trials may be inventively designed ad hoc to enhance the putative "efficacy" of a new drug; "surrogate" endpoints help avoid quantitative definition of outcomes of interest. One example of many from my story: after the potential toxicity of deferiprone, the drug in my conflict, was identified through sampling of liver tissue, subsequent studies avoided liver biopsies (although this is the only modality permitting evaluation of the toxicity). Instead, compliant researchers substituted blood tests as monitoring - these offered no clear information on this toxicity, but allowed company-paid researchers (truthfully) to assert that they "could not identify" liver damage.
Fisher's second focus is on the exploitative nature of Phase 1 trials. Many individuals who sign up are among society's most vulnerable, bearing what Fisher terms "imbricated stigma:" that is, they suffer from the "adverse [life] events" of economic insecurity, unemployment, systematic racism, lack of legal documentation and often, many of these factors. ("Imbrigation" refers to the overlapping pattern in which shingles are laid, creating a surface "stronger, more impenetrable and durable for its staggered structure"; p 12). Recruiting from this "fertile ground" of vulnerable individuals, Pharma exploits social inequalities, including tapping the unemployed and people of colour ( $p 56$ ).

Fisher's account of the advantages of testing drugs in a marginalised population resonates with my experience. My trials were aimed at improving treatment for patients with thalassemia, of which $90 \%$ percent of patients-that is, hundreds of thousands-live in low-income countries where governments refuse to pay for most drugs. Originally my hope had been that deferiprone might become affordable therapy in many emerging countries. Always important to remember: be careful what you wish for.

After many years, despite concerted efforts to obtain first line licensing by the CEO, every regulator worldwide has licensed deferiprone only as "last resort therapy" because of unanswered "questions about efficacy and safety."(10) In other words, all regulators have ruled that deferiprone may be prescribed only after two first-line therapies have "failed"- a rare occurrence.

But these are the rules for patients in high-resource countries. Throughout Asia, children with thalassemia are treated with "last resort" deferiprone as first-line treatment, (11) a practice uncritically justified by a prominent medical journal in a "Perspectives" endorsing deferiprone, (12) without disclosing that many children have sustained serious complications during these exposures (11).

It is not possible, of course, to be sure whether, if thalassemia were predominantly a disease of rich Americans rather than poorer Asians, this practice would be the subject of more critical oversight; just as it is impossible to know whether inclusion in Phase 1 trials of patients who are less vulnerable than most Phase 1 trial enrolees would change practices in these trials. What is clear is that not all patients have equal access to the kind of information on which their health and lives depend. This leads us to another important theme of Fisher's book: that of informed consent in Phase 1 trials.

It may surprise some to learn that Phase 1 trials of a drug may begin long before animal testing is concluded (p 133). In such circumstances, considering the precarious situations of many enrolled in Phase 1 trials, are these individuals really making an informed choice? Although uncommon, deaths do occur in Phase 1 trials. Yet many research staff regularly "discursively minimize" potential harms (p 139), regarding many volunteers as unable appropriately to weigh risks in part because "financial need is always believed to overshadow their 
attention to risk." (p 204).

In my own story, too, problems on the issue of informed consent arose and are ongoing. Years after the original conflict, deferiprone the drug in question, although unlicensed in Canada, was prescribed over years to patients in a Toronto hospital with no evidence of informed consent having been provided. No discernable actions were taken to protect patients from harms, including deaths $(13,14)$. It can only be hoped that provision of informed consent to these patients will not require another 25 years (9).

Finally, because Phase 1 trials are the first critical step to licensing, we should hope regulators, on which the public relies for assurance of drug safety, will identify misinformation and prevent the licensing of unsafe drugs. Alas, this is a point on which Fisher is clear: "Despite the appearance that FDAapproved drugs have been proven safe, this perception is just a myth, propagated by Pharma and supported by the regulatory system." (p 255)

This sobering statement rings true for those of us who have borne witness to what an FDA approval means, and what it does not. Many years after he prematurely terminated my trials, the CEO made application to the FDA to obtain licensing for deferiprone. His application prompted FDA to demand a formal inspection of my original data, which belatedly confirmed my decade-old concerns. FDA then demanded a new, controlled, trial - but after the CEO refused, the agency issued approval instead on data assembled from several small studies (15). Asked whether FDA had previously issued approval on data of such poor quality, an official replied "Not that I am aware of. I want to make sure this doesn't establish a precedent." (16)

But clearly, a precedent had already been established within a "culture of fear" at the FDA such that "as soon as a drug company says it is not going to do something, the FDA backs down." (17). Not altogether reassuring for any who still believe in the assurance of safety arising from FDA approval.

All this brings up the fundamental question as to benefits from a system in which Pharma manages virtually all drug trials, including Phase 1 trials. Clearly, the first beneficiaries include physicians and healthcare organisations: "supervision" of trials has become a significant revenue stream. It's also argued that uninsured individuals benefit from the medical "care" delivered in Phase 1 trials, a claim challenged by the reality that research participants lose access to any such care after a clinical trial ends (18).

Overall the principal lesson of Jill Fisher's excellent book is that only Pharma, and Pharma's hired hands, really benefit from the present system of drug testing. For everyone else, Pharma's domination of research, including of Phase 1 trials, is grim news. Grim for those who care about patient safety and the integrity of research; grim for anyone who attempts to stand up to scientifically fraudulent practices. And, ultimately, grim for the unknowing majority of citizens who never participate in a trial of a drug. That is because - in probably the strongest take-away message of Fisher's book - anything which the public "understands" about prescription drugs is limited to what Pharma wants us to understand.

\section{References}

1. Dunn A. Public trust in drugmakers is at an all-time low. Can biopharma recover? Biopharmadive.com. 2019 Sep 11[cited 2021 Apr 20]. Available from: https://www.biopharmadive.com/news/ pharma-industry-public-trust-gallup-business-roundtable/561986/

2. Angel J, Dearden N. The horrible history of Big Pharma: Why we can't leave pharmaceutical corporations in the driving seat of the Covid19 response. Global Justice. 2020 Dec 18[cited 2021 Apr 20] Available from: https://www.globaljustice.org.uk/resources/horriblehistory-big-pharma

3. Sismondo S. Ghost-Managed Medicine: Big Pharma's Invisible Hands. Mattering Press; 2018. Available from: https:// www.matteringpress.org/books/ghost-managed-medicine

4. Jureidini J, McHenry LB. The Illusion of Evidence-Based Medicine. Wakefield $\quad$ Press; $2020 . \quad$ Available from:https:// www.wakefieldpress.com.au/product.php?productid $=1588$

5. Eban K. Bottle of Lies: The Inside Story of the Generic Drug Boom. Ecco; 2020 Jun; Available from: https://www.harpercollins.com/ products/bottle-of-lies-katherine-eban?variant $=32206330134562$

6. Gøtzsche PC. Deadly medicines and organised crime How big pharma has corrupted healthcare. CRC Press; 2013.322 pp.

7. Drugs in 2017: A brief review. Rev Prescrire. 2018[cited 2021 Apr 20]; 38 (412):110-1. Available from: file:///D:/Admin/Downloads/ drugs_in_2017_a_brief_review\%20(3).pdf

8. Thompson J, Baird P, Downie J. Report of the Committee of inquiry on the case involving Dr Nancy Olivieri, The Hospital for Sick Children, the University of Toronto and Apotex Inc; 2001: 1-540. Available from: https://www.caut.ca/latest/publications/books/theolivieri-report

9. Healy D. Repetition Compulsion to the Death or Beyond? Davidhealy.org [website]. 2020 Mar 29[cited 2021 Apr 20]. Available from: https://davidhealy.org/repetition-compulsion-to-the-death-orbeyond/

10. Fisher SA, Brunskill SJ, Doree C, Chowdhury O, Gooding S, Roberts DJ. Oral deferiprone for iron chelation in people with thalassaemia. Cochrane Database Syst Rev. 2013 Aug 21;(8):CD004839.

11. Botzenhardt S, Felisi M, Bonifazi D, Del Vecchio GC, Putti MC, Kattamis A, et al. Long-term safety of deferiprone treatment in children from the Mediterranean region with beta-thalassemia major: the DEEP-3 multi-center observational safety study. Haematologica. 2018 Jan; 103(1):e1-e4.

12. Hider RC, Hoffbrand AV. The role of deferiprone in iron chelation. $N$ Engl J Med 2018 Nov 29; 379(22):2140-50.

13. Olivieri NF, Sabouhanian A, Gallie BL. Single-center retrospective study of the effectiveness and toxicity of the oral iron chelating drugs deferiprone and deferasirox. PLOS ONE. 2019 Feb 27; 14 (2): e0211942.

14 Schafer A. Institutional conflict of interest: attempting to crack the deferiprone mystery. J Med Ethics. Published online first on January 8, 2020:1-8.

15. Carome M. Wolfe SM. Letter to FDA opposing approval of deferiprone. Public Citizen. 2011 Oct 12[cited 2021 Apr 20]. Available from: $\quad$ https://www.citizen.org/article/letter-to-fda-opposingapproval-of-deferiprone/

16. Goldberg P. How Low Can You Go? ODAC accepts retrospective study, data from Europe. The Cancer Letter. 2011 Sep[cited $2021 \mathrm{Apr}$ 20]; 37(36): 1-4. Available from: file:///D:/Admin/Downloads/TCL3736.pdf

17. Griffiths K. 2005. The Interview: David Graham, FDA Whistleblower; Drug tsar who took on the system. The Independent. 2005 Feb 12[cited 2021 Apr 20]. Available from: https:// www.independent.co.uk/news/business/the-interview-davidgraham-fda-whistleblower-drug-tsar-who-took-on-the-system1530328.html

18. Wilson MH. Inequity in the market place BMJ. 2008 Sep 23; 337:a: 1772. Doi: https://doi.org/10.1136/bmj.a1772. 